\title{
The effect of compression therapy on quality of life in patients with chronic venous disease: a comparative 6-month study
}

\author{
Andrzej Berszakiewicz ${ }^{1,2}$, Janusz Kasperczyk ${ }^{3}$, Aleksander Sieroñ ${ }^{1,4}$, Zbigniew Krasiński $^{5}$, Armand Cholewka $^{6}$, \\ Agata Stanek ${ }^{7}$
}

\begin{abstract}
1Department of Internal Medicine, Angiology and Physical Medicine, No. 2 Specialist Hospital, Bytom, Poland ${ }^{2}$ Fresenius Dialysis Centre, No. 38 in Oswiecim, Fresenius Nephrocare Polska, Oswiecim, Poland ${ }^{3}$ Chair and Department of Environmental Medicine and Epidemiology, Medical University of Silesia, Zabrze, Poland ${ }^{4}$ Department of Physiotherapy, Jan Dugosz University, Czestochowa, Poland ${ }^{5}$ Department of General and Vascular Surgery, Poznan University of Medical Sciences, Poznan, Poland ${ }^{6}$ Department of Medical Physics, Chelkowski Institute of Physics, University of Silesia, Katowice, Poland ${ }^{7}$ Department of Internal Medicine, Angiology and Physical Medicine, Medical University of Silesia, Faculty of Medicine in Zabrze, Bytom, Poland
\end{abstract}

Adv Dermatol Allergol 2021; XXXVIII (3): 389-395 DOI: https://doi.org/10.5114/ada.2020.92277

\begin{abstract}
Introduction: Chronic venous diseases (CVD), because of its chronic and progressive nature, impairs patients' quality of life (Qol).

Aim: To compare the QoL in patients with primary superficial venous insufficiency at different stages before and after compression therapy (CT).

Material and methods: We compared the change in the QoL parameters from baseline to the end of a 6-month compression therapy. 180 subjects were enrolled. They were subdivided into 6 equal subgroups according to CEAP classes. The QoL was assessed using questionnaires, the general SF-36V2 and the disease-specific CIVIQ-20. At the beginning and after the completion of the study intervention, the severity of CVD was assessed in each patient using CEAP and VCSS. The pain intensity was assessed using the numerical rating scale.

Results: The CT reduced the severity of CVD, which translated into the increased size of C2 an d C5 subgroups, and reduced size of C3 and C6 subgroups. Another marker of reduced severity of CVD after CT was a significant reduction in VCSS scores in C1, and C3-C6 subgroups. A 6-month CT was associated with a significant QoL improvement in all CEAP class-based subgroups, across all individual and composite domains of SF-36v2, as well as dimensions and GIS of CIVIQ-20. Similarly, there was a significant pain reduction reported in all CEAP class-based subgroups. Conclusions: Compression therapy using ready-made compression hosiery significantly affects the quality of life in patients with chronic venous disease at all its stages, CEAP classes C1-C6.
\end{abstract}

Key words: compression therapy, chronic venous diseases, quality of life.

\section{Introduction}

According to the WHO, health is not merely the absence of disease or infirmity, but a state of complete physical, mental and social well-being. It, therefore, assumes maintenance of well-being and satisfactory function across all aspects of life $[1,2]$. Each curative treatment aims at returning to complete health. In patients with chronic diseases, the ability to maintain highest achievable quality of life (QoL) is an additional marker of treatment success [1]. WHO defines the QoL as "the individual's perception of their position in life in the context of the culture and value systems in which they live and in relation to their goals, expectations, standards and concerns". It is affected by a number of interrelated factors, including but not limited to physical health, interpersonal relationships and environmental attributes which an in-

Address for correspondence: Prof. Agata Stanek MD, PhD, Department of Internal Diseases, Angiology and Physical Medicine, Medical University of Silesia, 15 Batorego St, 41-902 Bytom, Poland, phone/fax: +48 32 7861630, e-mail: astanek@tlen.pl Received: 25.11.2019, accepted: 4.12.2019. 
dividual considers important [3]. QoL affects all domains of life crucial for an individual's existence. Discussed in the context of health and disease, the QoL is usually termed health-related quality of life (HRQoL) [3, 4]. The QoL is assessed using different questionnaire measures, both general and disease-specific.

CVD affects $30-50 \%$ of adult population and its chronic, progressive nature significantly impairs the quality of life $[5,6]$. The higher severity of CVD, expressed as CEAP class, the worse the HRQoL [7]. The QoL is assessed in patients with CVD using different questionnaire measures, both general and disease-specific [3, 7]. The 36-item Short Form Health survey (SF-36) is a recommended general QoL measure. The CVD-specific validated QoL measures include Chronic Venous Insufficiency QoL Questionnaire (CIVIQ-20), Venous Insufficiency Epidemiological and Economic Study (VEINES-QoL), and Aberdeen Varicose Vein Questionnaire (AVVQ) [8, 9].

Compression therapy $(\mathrm{CT})$ is an established treatment of CVD with a plethora of clinical studies supporting its efficacy $[10,11]$. However, the number of papers evaluating the changes in quality of life after using CT is relatively low.

\section{Aim}

The aim of the study was to assess the quality of life in patients with primary superficial venous insufficiency at different stages (CEAP classes) after CT. Superficial venous insufficiency is considered a primary condition, as it is of undetermined origin, established genetic links and lifestyle-related [12].

\section{Material and methods}

The study protocol was approved by the Bioethical Committee of the Medical University of Silesia in Katowice (approval no. KNW/0022/KB/103/16).

The study was carried out at the Department of Internal Diseases, Angiology and Physical Medicine in Bytom, Medical University of Silesia in Katowice, as well as Vascular Clinic in Koszęcin. One hundred and eighty subjects with CVD due to primary superficial venous insufficiency, previously untreated with $\mathrm{CT}$, were enrolled in the survey-based study. The sample was divided evenly, into subgroups based on the CVD severity assessed using CEAP classification (C1 to C6, 30 subjects each). The exclusion criteria were chronic comorbidities likely to affect the QoL, such as malignancies, severe chronic obstructive pulmonary disease (COPD), respiratory failure, severe heart failure, rheumatoid arthritis, any locomotor system pathology making the patient non-ambulant, with associated chronic leg pain, mental health problems making the patient uncooperative, as well as pregnancy and postpartum. Furthermore, the patients with a history of deep vein thrombosis (DVT) and those with a history of invasive treatment of CVD within 2 years prior to enrolment, were excluded. Patients after changes to CVD treatment made throughout the study were excluded, just as those non-compliant with their prescribed CT regimen, preferring bandage-only $\mathrm{CT}$ and those who, due to leg deformity or size, posed a significant challenge selecting and fitting appropriate compression hosiery products. Finally, the presence of contraindications to CT was an exclusion criterion. During the first visit/assessment, ready-made compression hosiery was prescribed (stockings, tights, knee-high socks), with the compression level selected individually based on the international guidelines [10, 11, 13-15]. Each patient was educated on the need to wear their prescribed compression products daily for not less than $8 \mathrm{~h} /$ day. The compression hosiery was always removed for the night. In patients with VLUs, ready-made 2-in-1 compression systems, with a liner worn for $24 \mathrm{~h}$, were used. During the first visit, the consultant angiologist assessed the severity of CVD according to the Clinical-Etiology-Anatomy-Pathophysiology (CEAP) class and Venous Clinical Severity Score (VCSS). The CEAP classification is intended to grade CVD severity based on current clinical presentation [16]. VCSS, on the other hand, enables a longitudinal comparison of CVD symptom severity in a group receiving specific treatment and is recommended as a preferred measure in clinical research [16]. Lower extremity Doppler scan was performed in all patients using Logiq 5 and Logiq 7 scanners. The ankle-brachial index (ABI) and the body mass index (BMI) were calculated for each enrolled patient. It was followed by a survey, which ascertained social and demographic characteristics of the patients, alongside their CVD risk factors and pain severity assessed using the Numerical Rating Scale (NRS). The NRS is a horizontal, linear scale ranging from 0 , which corresponds to no pain, to 10 , which corresponds to the most severe imaginable pain ever. It is a validated, reliable measure [17]. Each subject was requested to complete two Quality of Life measures. The first, general, non-disease-specific questionnaire was the Medical Outcomes Study 36-Items Short-Form Health Survey version 2 (SF-36v2) consisting of 36 items across 11 categories, which correspond to 8 quality of life domains, including Physical Functioning (PF), Role Physical (RP), Bodily Pain (BP), General Health $(\mathrm{GH})$, Vitality (VT), Social Functioning (SF), Role Emotional (RE), and Mental Health (MH). Two composite scores were computed, the Physical Health Summary (PHS) and the Mental Health Summary (MHS) scores. The PHS was computed as a mean of the PF, RP, BP and GH scores. The MHC was computed as a mean of the VT, SF, RE and $\mathrm{MH}$ scores [3]. The higher the score in each domain, the better the quality of life. The Polish language version of the questionnaire was made available for use based on license no. SLAQM035217-CT177581-OP052675. Another questionnaire was a validated, Polish version of CVD-specific CIVIQ-20 authored by professor Launois, the transla- 
tion and validation of which was supported by a research grant from Servier. The measure consists of 20 items pertaining to 4 QoL dimensions, namely: pain dimension (4 items), physical dimension (4 items), social dimension (3 items) and a psychological dimension (9 items). The dimension scores are calculated as a total of relevant item scores. The total score, known as the Global Index Score (GIS) is computed using the formula $[8,18]$. The lower the score in each domain and GIS, the better the quality of life. The measure was originally intended for CEAP classes C2-C5 and is used in particular in CEAP C2 patients [19]. With time, CEAP CO and C1 patients were also assessed using CIVIQ-20. Due to item content and design, it is not intended for CEAP C6 patients, i.e. those with active VLUs [20]. There are, however, studies which report administrating validated translations of CIVIQ-20 to C6 patients in an attempt to assess their QoL [21, 22].

After 6 months of CT, all patients were invited to a follow-up visit, during which they were clinically re-assessed (CEAP, VCSS). Also, the survey as described above was repeated, excluding the items pertaining to socio-demographic characteristics and CVD risk factors, as these had been ascertained before.

\section{Statistical analysis}

The questionnaire data were checked for completeness, entered into the database and analysed statistically using the Statistica bundle. The between-group differences were determined using the $T$-test or Mann-Whitney $U$-test. The paired $T$-test and Wilcoxon signed-rank test were used for parametric and non-parametric quantitative variables, respectively. For qualitative variables, the $\chi^{2}$ and the maximum likelihood estimation (MLE) were used. The $p<0.05$ was considered significant for all comparisons.

\section{Results}

The demographic and social characteristics of the study group are shown in Table 1 . The mean patient-reported CT wear time was $9.33 \pm 1.42$, $9.3 \pm 1.5$, $9.66 \pm 1.7$, $10.2 \pm 1.5,9.7 \pm 1.7$, and $10.4 \pm 1.6 \mathrm{~h}$ in CEAP classes C 1 to C6, respectively. At the end of the study, changes in CEAP class-based subgroup sizes were noticed. The C2 group grew from 30 to 49 subjects, whereas the C3 group decreased in size from 30 to 11 subjects. Similarly, the C5 group grew from 30 to 52 at the expense of the $\mathrm{C} 6$ group size reduction from 30 to only 8 . The decreased size of the C6 subgroup was associated with a complete resolution of venous leg ulcerations in 22 subjects. After 6 months, there was a significant reduction in CVD severity assessed using VCSS in all CEAP class-based subgroups except for C2 (Figure 1).

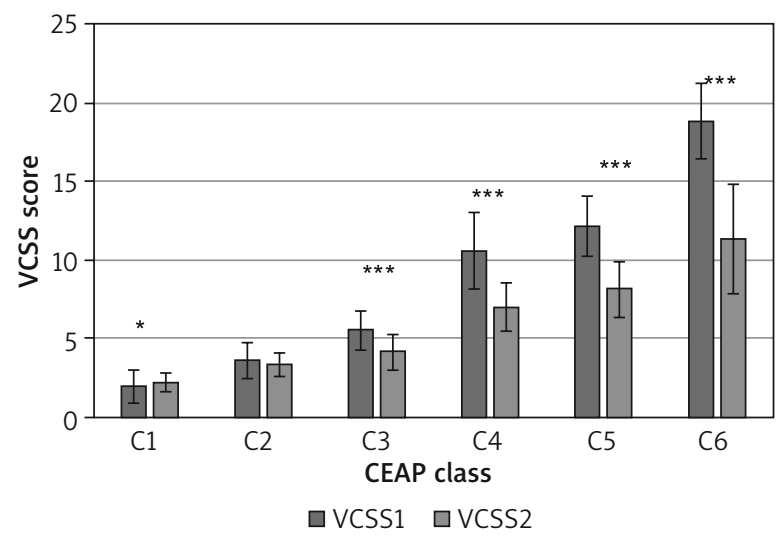

Figure 1. The mean $( \pm S D)$ Venous Clinical Severity Score (VCSS) at two time - points (VCSS1) baseline and after the end of CT (VCSS2) in individual CEAP class-based patient groups with a statistical difference analysis $\left({ }^{*} p<0.05\right.$, $\left.{ }^{* * *} p<0.0001\right)$

Table 1. Demographic and social characteristics of the study sample by CEAP class

\begin{tabular}{|c|c|c|c|c|c|c|c|}
\hline $\begin{array}{l}\text { CEAP } \\
\text { Class }\end{array}$ & $\begin{array}{c}\text { Sex } \\
w / m(\%)\end{array}$ & $\begin{array}{l}\text { Age [years] } \\
\text { mean (SD) }\end{array}$ & $\begin{array}{c}\mathrm{BMI}\left[\mathrm{kg} / \mathrm{m}^{2}\right] \\
\text { mean }(\mathrm{SD})\end{array}$ & $\begin{array}{l}\text { Place of residence } \\
\text { urban/rural (\%) }\end{array}$ & $\begin{array}{c}\text { Professionally active } \\
\text { yes/no (\%) }\end{array}$ & $\begin{array}{l}\text { Living alone } \\
\text { yes/no (\%) }\end{array}$ & $\begin{array}{c}\text { Family support } \\
\text { yes/no (\%) }\end{array}$ \\
\hline 1 & $\begin{array}{c}29 / 1 \\
(96.67 / 3.33)\end{array}$ & $\begin{array}{l}35.40 \\
( \pm 4.16)\end{array}$ & $\begin{array}{c}25.53 \\
( \pm 1.70)\end{array}$ & $\begin{array}{c}24 / 6 \\
(80 / 20)\end{array}$ & $\begin{array}{c}30 / 0 \\
(100 / 0)\end{array}$ & $\begin{array}{c}7 / 23 \\
(23 / 33)\end{array}$ & $\begin{array}{c}30 / 0 \\
(100 / 0)\end{array}$ \\
\hline 2 & $\begin{array}{c}25 / 5 \\
(83.33 / 16.67)\end{array}$ & $\begin{array}{c}45.40 \\
( \pm 10.25)\end{array}$ & $\begin{array}{l}26.85 \\
( \pm 1.50)\end{array}$ & $\begin{array}{c}20 / 10 \\
(66.67 / 33.33)\end{array}$ & $\begin{array}{c}27 / 3 \\
(90 / 10)\end{array}$ & $\begin{array}{c}4 / 26 \\
(13.33 / 86.67)\end{array}$ & $\begin{array}{c}30 / 0 \\
(100 / 0)\end{array}$ \\
\hline 3 & $\begin{array}{c}24 / 6 \\
(80.0 / 20.0)\end{array}$ & $\begin{array}{c}47.96 \\
( \pm 7.29)\end{array}$ & $\begin{array}{c}27.60 \\
( \pm 2.76)\end{array}$ & $\begin{array}{c}15 / 15 \\
(50 / 50)\end{array}$ & $\begin{array}{c}25 / 5 \\
(83.33 / 16.67)\end{array}$ & $\begin{array}{c}4 / 26 \\
(13.33 / 86.67)\end{array}$ & $\begin{array}{c}30 / 0 \\
(100 / 0)\end{array}$ \\
\hline 4 & $\begin{array}{c}14 / 16 \\
(46.67 / 53.33)\end{array}$ & $\begin{array}{c}54.00 \\
( \pm 7.24)\end{array}$ & $\begin{array}{c}28.75 \\
( \pm 2.30)\end{array}$ & $\begin{array}{c}17 / 13 \\
(56.67 / 43.33)\end{array}$ & $\begin{array}{c}18 / 12 \\
(60 / 40)\end{array}$ & $\begin{array}{c}7 / 23 \\
(23.33 / 76.67)\end{array}$ & $\begin{array}{c}30 / 0 \\
(100 / 0)\end{array}$ \\
\hline 5 & $\begin{array}{c}17 / 13 \\
(56.67 / 43.33) \\
\end{array}$ & $\begin{array}{c}58.4 \\
( \pm 6.39) \\
\end{array}$ & $\begin{array}{c}29.52 \\
( \pm 2.89) \\
\end{array}$ & $\begin{array}{c}20 / 10 \\
(66.67 / 33.33) \\
\end{array}$ & $\begin{array}{c}12 / 18 \\
(40 / 60)\end{array}$ & $\begin{array}{c}5 / 25 \\
(16.67 / 83.33) \\
\end{array}$ & $\begin{array}{c}28 / 2 \\
(93.33 / 6.67) \\
\end{array}$ \\
\hline 6 & $\begin{array}{c}19 / 11 \\
(63.33 / 36.67)\end{array}$ & $\begin{array}{c}58.53 \\
( \pm 10.86)\end{array}$ & $\begin{array}{c}30.38 \\
( \pm 3.54)\end{array}$ & $\begin{array}{c}19 / 11 \\
(63.33 / 36.67)\end{array}$ & $\begin{array}{c}10 / 20 \\
(33.33 / 66.66)\end{array}$ & $\begin{array}{c}6 / 24 \\
(20 / 80)\end{array}$ & $\begin{array}{c}28 / 2 \\
(93.33 / 6.67)\end{array}$ \\
\hline
\end{tabular}

CEAP - Clinical, Etiological, Anatomical and Pathophysiological grade, BMI - body mass index, SD - standard deviation, w-women, $m$ - men. 
Table 2. The mean ( \pm SD) QoL scores in SF-36v2 at baseline and after 6 months of CT

\begin{tabular}{|c|c|c|c|c|c|c|c|c|}
\hline \multirow{3}{*}{$\begin{array}{l}\text { CEAP } \\
\text { Class }\end{array}$} & \multicolumn{8}{|c|}{ Domains } \\
\hline & $\begin{array}{c}\mathrm{PF} \\
\text { before/after }\end{array}$ & $\begin{array}{c}\text { RP } \\
\text { before/after }\end{array}$ & $\begin{array}{c}\text { BP } \\
\text { before/after }\end{array}$ & $\begin{array}{c}\text { GH } \\
\text { before/after }\end{array}$ & $\begin{array}{c}\text { VT } \\
\text { before/after }\end{array}$ & $\begin{array}{c}\text { SF } \\
\text { before/after }\end{array}$ & $\begin{array}{c}\mathrm{RE} \\
\text { before/after }\end{array}$ & $\begin{array}{c}\text { MH } \\
\text { before/after }\end{array}$ \\
\hline & $P$-value & $P$-value & $P$-value & $P$-value & $P$-value & $P$-value & $P$-value & $P$-value \\
\hline \multirow[t]{2}{*}{1} & $\begin{array}{c}76.33( \pm 12.8) / \\
98.66( \pm 2.9)\end{array}$ & $\begin{array}{c}64.16( \pm 13.2) / \\
98.54( \pm 4.2)\end{array}$ & $\begin{array}{c}48.2( \pm 16.72) / \\
98.93( \pm 4.0)\end{array}$ & $\begin{array}{l}29.13( \pm 24.3) / \\
88.46( \pm 12.9)\end{array}$ & $\begin{array}{c}40.62( \pm 16.55) / \\
82.91( \pm 9.27)\end{array}$ & $\begin{array}{c}49.16( \pm 22.7) / \\
98.75( \pm 3.8)\end{array}$ & $\begin{array}{c}70.83( \pm 13.79) / \\
99.44( \pm 2.1)\end{array}$ & $\begin{array}{c}46.66( \pm 16.6) / \\
87.16( \pm 5.9)\end{array}$ \\
\hline & $<0.0001$ & $<0.0001$ & $<0.0001$ & $<0.0001$ & $<0.0001$ & $<0.0001$ & $<0.0001$ & $<0.0001$ \\
\hline \multirow[t]{2}{*}{2} & $\begin{array}{c}72.66( \pm 16.33) / \\
97.66( \pm 4.68)\end{array}$ & $\begin{array}{c}53.53( \pm 15.28) / \\
98.54( \pm 4.24)\end{array}$ & $\begin{array}{c}44.06( \pm 20.49) / \\
96.4( \pm 7.6)\end{array}$ & $\begin{array}{c}25.73( \pm 17.19) / \\
88.13( \pm 9.67)\end{array}$ & $\begin{array}{l}42.08( \pm 15.9) / \\
80.62( \pm 10.03)\end{array}$ & $\begin{array}{c}46.66( \pm 24.1) / \\
97.5( \pm 6.88)\end{array}$ & $\begin{array}{l}57.5( \pm 15.05) / \\
98.88( \pm 3.61)\end{array}$ & $\begin{array}{c}46.33( \pm 16.23) \\
85.5( \pm 8.44)\end{array}$ \\
\hline & $<0.0001$ & $<0.0001$ & $<0.0001$ & $<0.0001$ & $<0.0001$ & $<0.0001$ & $<0.0001$ & $<0.0001$ \\
\hline \multirow[t]{2}{*}{3} & $\begin{array}{l}63.16( \pm 15.7) / \\
95.83( \pm 4.56)\end{array}$ & $\begin{array}{l}48.33( \pm 12.9) / \\
95.62( \pm 7.36)\end{array}$ & $\begin{array}{c}33.43( \pm 14.5) / \\
91.8( \pm 10.66)\end{array}$ & $\begin{array}{c}12.23( \pm 11.93) / \\
85.93( \pm 9.75)\end{array}$ & $\begin{array}{c}29.37( \pm 11.38) / \\
76.45( \pm 8.15)\end{array}$ & $\begin{array}{c}35.83( \pm 21.95) / \\
96.25( \pm 6.68)\end{array}$ & $\begin{array}{c}50.55( \pm 15.46) / \\
94.16( \pm 10.06)\end{array}$ & $\begin{array}{l}35.83( \pm 9.12) / \\
83.66( \pm 6.81)\end{array}$ \\
\hline & $<0.0001$ & $<0.0001$ & $<0.0001$ & $<0.0001$ & $<0.0001$ & $<0.0001$ & $<0.0001$ & $<0.0001$ \\
\hline \multirow[t]{2}{*}{4} & $\begin{array}{c}55.83( \pm 17.66) / \\
89.66( \pm 6.68)\end{array}$ & $\begin{array}{l}39.16( \pm 18.04) / \\
89.79( \pm 13.68)\end{array}$ & $\begin{array}{c}22.56( \pm 12.95) / \\
83.26( \pm 9.37)\end{array}$ & $\begin{array}{c}13.33( \pm 14.81) / \\
79.1( \pm 11.13)\end{array}$ & $\begin{array}{c}20.41( \pm 13.12) / \\
71.87( \pm 6.71)\end{array}$ & $\begin{array}{l}31.25( \pm 21.46) / \\
92.08( \pm 10.62)\end{array}$ & $\begin{array}{l}44.72( \pm 19.01) / \\
90.83( \pm 11.65)\end{array}$ & $\begin{array}{l}26.5( \pm 13.2) / \\
81.16( \pm 6.25)\end{array}$ \\
\hline & $<0.0001$ & $<0.0001$ & $<0.0001$ & $<0.0001$ & $<0.0001$ & $<0.0001$ & $<0.0001$ & $<0.0001$ \\
\hline \multirow[t]{2}{*}{5} & $\begin{array}{c}47.00( \pm 12.29) \\
85.33( \pm 7.87)\end{array}$ & $\begin{array}{r}26.66( \pm 13.12) / \\
81.45( \pm 14.99)\end{array}$ & $\begin{array}{c}14.00( \pm 14.47) / \\
73.53( \pm 11.85)\end{array}$ & $\begin{array}{l}6.16( \pm 10.05) / \\
75.53( \pm 10.94)\end{array}$ & $\begin{array}{c}15.83( \pm 14.47) / \\
70.62( \pm 7.18)\end{array}$ & $\begin{array}{c}17.91( \pm 12.57) / \\
82.5( \pm 12.1)\end{array}$ & $\begin{array}{c}30.27( \pm 17.84) / \\
84.16( \pm 13.72)\end{array}$ & $\begin{array}{l}22.0( \pm 16.1) / \\
80.0( \pm 7.54)\end{array}$ \\
\hline & $<0.0001$ & $<0.0001$ & $<0.0001$ & $<0.0001$ & $<0.0001$ & $<0.0001$ & $<0.0001$ & $<0.0001$ \\
\hline \multirow[t]{2}{*}{6} & $\begin{array}{l}21.33( \pm 17.36) / \\
78.99( \pm 12.82)\end{array}$ & $\begin{array}{c}10.62( \pm 13.24) / \\
81.25( \pm 19.14)\end{array}$ & $\begin{array}{c}0.00( \pm 0.00) / \\
66.56( \pm 13.26)\end{array}$ & $\begin{array}{c}1.00( \pm 3.8) / \\
66.43( \pm 13.99)\end{array}$ & $\begin{array}{l}7.29( \pm 9.99) / \\
64.68( \pm 10.8)\end{array}$ & $\begin{array}{c}0.41( \pm 2.28) / \\
72.91( \pm 15.77)\end{array}$ & $\begin{array}{l}14.16( \pm 15.18) / \\
82.22( \pm 18.66)\end{array}$ & $\begin{array}{l}9.5( \pm 10.2) / \\
73.9( \pm 9.61)\end{array}$ \\
\hline & $<0.0001$ & $<0.0001$ & $<0.0001$ & $<0.0001$ & $<0.0001$ & $<0.0001$ & $<0.0001$ & $<0.0001$ \\
\hline
\end{tabular}

CEAP - Clinical, Etiological, Anatomical and Pathophysiological grade, SF-36v2 domains: PF - Physical Functioning, RP - Role Physical, BP - Bodily Pain, $\mathrm{GH}$ - General Health, VT - Vitality, RE-Role Emotional, MH-Mental Health, $p$-statistical significance.

There was a significant reduction in pain severity assessed using NRS in all CEAP class-based subgroups (Figure 2).

There was a significant change of SF-36v2 scores reflecting the improved QoL across all individual and composite domains. The improvement was seen in all

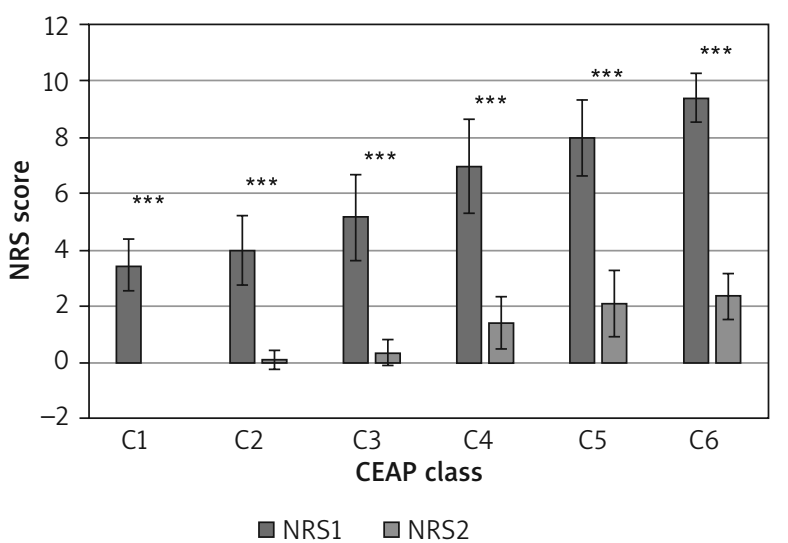

Figure 2 . The mean $( \pm S D)$ numeric rating scale scores at two time-points: baseline (NRS1) and after the end of CT (NRS2) by CEAP class, with a statistical difference analysis $\left({ }^{* * *} p<0.0001\right)$
CEAP class-based subgroups. The largest improvement was noted in the CEAP C6 subgroup, where the scores increased the most in all individual domains (except for $\mathrm{GH}$ ) and collective scores (Table 2, Figure 3).

The re-assessment with CIVIQ-20 after 6 months CT demonstrated a significant improvement in quality of life

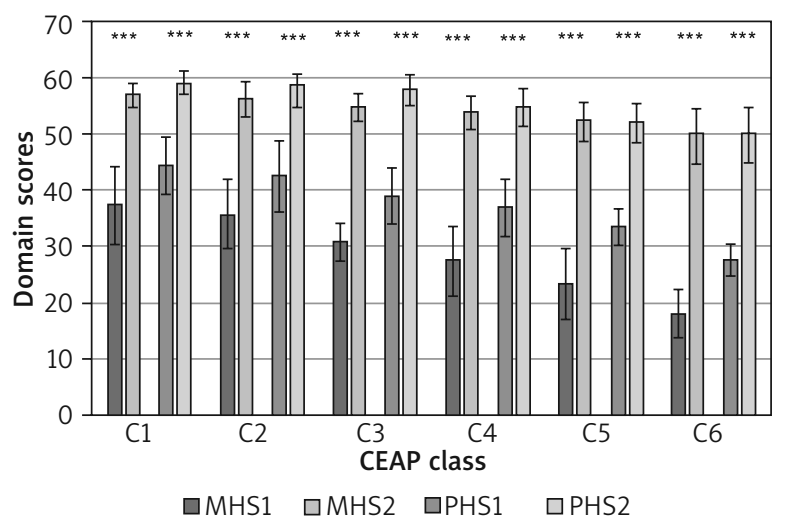

Figure 3. A comparison of means $( \pm S D)$ for the SF-36v2 domains: Mental Health Summary (MHS) and Physical Health Summary (PHS) at two time-points: (1) baseline, and (2) after the end of CT, by CEAP class, with a statistical difference analysis $\left.{ }^{* * *} p<0.0001\right)$ 
Table 3. The mean ( \pm SD) QoL scores in CIVIQ-2 at baseline and after 6 months of CT

\begin{tabular}{|c|c|c|c|c|}
\hline \multirow{3}{*}{$\begin{array}{l}\text { CEAP } \\
\text { class }\end{array}$} & \multicolumn{4}{|c|}{ Dimensions } \\
\hline & $\begin{array}{l}\text { Pain dimension } \\
\text { before/after }\end{array}$ & $\begin{array}{l}\text { Physical dimension } \\
\text { before/after }\end{array}$ & $\begin{array}{l}\text { Social dimension } \\
\text { before/after }\end{array}$ & $\begin{array}{l}\text { Psychological dimension } \\
\text { before/after }\end{array}$ \\
\hline & $P$-value & $P$-value & $P$-value & $P$-value \\
\hline \multirow[t]{2}{*}{1} & $11.8( \pm 2.92) / 4.16( \pm 0.37)$ & $8.43( \pm 2.51) / 4.0( \pm 0.00)$ & $5.9( \pm 2.18) / 3.03( \pm 0.18)$ & $19.53( \pm 6.75) / 10.1( \pm 0.8)$ \\
\hline & $<0.0001$ & $<0.0001$ & $<0.0001$ & $<0.0001$ \\
\hline \multirow[t]{2}{*}{2} & $12.4( \pm 3.74) / 4.96( \pm 1.21)$ & $9.83( \pm 3.48) / 4.3( \pm 0.7)$ & $6.36( \pm 3.28) / 3.16( \pm 0.53)$ & $20.86( \pm 8.08) / 11.1( \pm 1.6)$ \\
\hline & $<0.0001$ & $<0.0001$ & $<0.0001$ & $<0.0001$ \\
\hline \multirow[t]{2}{*}{3} & $14.33( \pm 2.91) / 5.6( \pm 1.45)$ & $11.66( \pm 2.92) / 4.8( \pm 1.12)$ & $7.6( \pm 3.26) / 3.3( \pm 0.59)$ & $25.93( \pm 8.25) / 11.0( \pm 1.17)$ \\
\hline & $<0.0001$ & $<0.0001$ & $<0.0001$ & $<0.0001$ \\
\hline \multirow[t]{2}{*}{4} & $16.6( \pm 3.2) / 6.7( \pm 1.23)$ & $13.53( \pm 3.33) / 5.73( \pm 1.48)$ & $8.9( \pm 3.35) / 3.76( \pm 0.85)$ & $28.2( \pm 8.5) / 12.23( \pm 1.25)$ \\
\hline & $<0.0001$ & $<0.0001$ & $<0.0001$ & $<0.0001$ \\
\hline \multirow[t]{2}{*}{5} & $18.06( \pm 2.61) / 8.43( \pm 2.22)$ & $15.2( \pm 2.24) / 3.36( \pm 12.49)$ & $10.8( \pm 2.1) / 4.56( \pm 1.79)$ & $32.86( \pm 6.44) / 14.0( \pm 2.31)$ \\
\hline & $<0.0001$ & $<0.0001$ & $<0.0001$ & $<0.0001$ \\
\hline \multirow[t]{2}{*}{6} & $19.73( \pm 0.69) / 8.6( \pm 1.61)$ & $17.3( \pm 1.7) / 7.83( \pm 2.18)$ & $13.63( \pm 1.06) / 5.66( \pm 1.88)$ & $40.33( \pm 4.16) / 15.9( \pm 3.36)$ \\
\hline & $<0.0001$ & $<0.0001$ & $<0.0001$ & $<0.0001$ \\
\hline
\end{tabular}

CEAP - Clinical, Etiological, Anatomical and Pathophysiological grade, CIVIQ-20 dimensions: pain dimension, physical dimension, social dimension, and psychological dimension, $p$-statistical significance.

across all four basic QoL domains and in GIS, in all CEAP class-based subgroups (Table 3, Figure 4).

There was no treatment-related adverse event reported during the compression therapy.

\section{Discussion}

The QoL assessment in patients with CVD demonstrated a significant disease-related impairment in QoL, which worsens gradually with disease progression [23, 24]. The lowest QoL is observed in patients with CVD CEAP class C6. Whereas the number of papers to assess QoL in patients with CVD after treatment is limited, there is evidence that CVD treatment positively affects QoL $[19,25]$. The majority of research papers focus on assessing the efficacy of medical and invasive CVD treatments with only few evaluating the QoL after CT, in chosen, usually higher CEAP classes. Our study assessed QoL in patients at all stages of CVD, CEAP classes C1 to C6, with a follow-up period of 6 months, longer than other comparable studies. The subjects were evaluated for any changes to their clinical presentation and quality of life.

CT reduces intraluminal venous pressure, counteracts the gravity, improves venous outflow and reduces venous stasis thereby slowing clinical progression or actually improving the symptoms of CVD. In our study, we demonstrated a reduction in severity of clinical CVD symptoms after 6 months of CT. It was reflected in a numerical shift within CEAP class-based subgroup sizes and a change in VCSS scores. The size of C2 and C5 subgroups increased, which was related to reduced oedema,

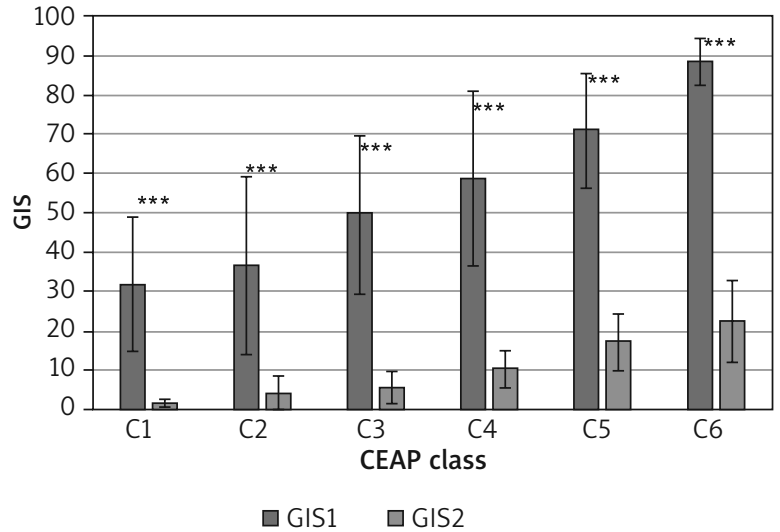

Figure 4. The mean ( \pm SD) global index score (GIS) of CIVIQ-20 at two time-points: (1) baseline, and (2) after the end of CT, with a statistical difference analysis $\left({ }^{\star \star *} p<0.0001\right)$

skin lesions of healing of venous leg ulcers (VLUs). The VCSS assessment confirmed severity reduction of clinical CVD symptoms in all CEAP class-based subgroups. In classes C1, and C3 to C6, the VCSS score change was significant. The non-significant change in class C2 can be explained by the specificity of the VCSS scale, where additional points are awarded for using CT. Regular use of CT gives additional 3 points, which significantly changes the total score, especially in the lowest CEAP class-based subgroups [26]. The key clinical symptoms affecting changes in QoL are pain and oedema [22, 27]. Pain is the main complaint reported by patients with CVD 
which makes them seek medical advice [21]. It occurs at any stage of CVD and increases in incidence and severity with disease progression. Pain is reported by $64-82 \%$ of patients with VLUs [28]. Pain limits physical activity and secondarily reduces employability, worsening patient social isolation and dependence. It also affects patient mental health, decreasing their self-esteem. Chronic pain causes anxiety, helplessness, and resignation with lack of trust in treatment efficacy [23]. Nocturnal pains in patients with VLUs deprive them of sleep causing insomnia and exhaustion [29]. It was confirmed that appropriately selected and fitted compression therapy, reduces pain in approximately $90 \%$ of patients with chronic venous insufficiency (CVI) [30]. In our study, the numeric rating scale confirmed a significant pain reduction after CT. It was observed in each CEAP class subgroup. The highest pain reduction was observed in the C6 subgroup.

The main aim of the study was to assess the QoL after using CT. The QoL is impaired in patients with CVD across all measurable domains. The magnitude of impairment differs between domains, depending on severity of CVD. For example, patients with varicose veins experience impairment in physical rather than mental QoL domains [31]. In patients with VLUs, the QoL impairment increases gradually, which is reflected in worsening physical (RP, PF, BP, GH) and mental (SR, RE) scores [24]. The largest CVD-related QoL deterioration is seen in the pain domain [21,32].

In 2005, Andreozzi et al. evaluated the effect of 4-month CT on QoL in patients with CVI (only CEAP classes C2 to C5 were studied) and demonstrated a significant improvement across all domains in C3-C5 CEAP class-based subgroups. In the C2 class, however, whereas some improvement was demonstrated across all SF-36v2 domains, it was non-significant in the PF, GH and $\mathrm{MH}$ domains and significant in the remaining domains [19]. This was explained by the absence of quality of life impairment across the areas represented by these domains at baseline, as well as the small sample size [19]. In our study, there was a significant score improvement across all domains of the SF-36v2 in all enrolled CEAP classes, i.e. C1-C6. It should be noted that the size of the C2 subgroup was similar to that of Andreozzi et al. (30 vs. 27). The difference in findings can, therefore, be explained by our longer follow-up period or patient-declared 100\% compliance with $\mathrm{CT}$ recommendations.

After 6 months of the study, the highest score improvements were observed in the $\mathrm{GH}$ and BP domains, which represent general health and bodily pain. The largest QoL improvement across all basic domains (PF, RP, BP, $\mathrm{VT}, \mathrm{SF}, \mathrm{RE}$ and $\mathrm{MH}$ ) and both composite domains (PHS, MHS) of the SF-36V2 was observed in subjects classed as CEAP C6 at baseline. It should be noted that these patients had the lowest baseline QoL.
The assessment using the CVD-specific measure, CIVIQ-20, also confirmed improved QoL in all CEAP classbased subgroups. Significant score changes were noted across all four basic dimensions as well as GIS. Just as it was the case with SF-36v2 scores, the higher the CEAP class, the larger QoL improvement was observed. The enrolment of patients representing all CEAP classes, C1-C6, was only possible due to the availability of ready-made 2-in-1 compression systems for patients with VLUs, that is, the CEAP C6 class. These systems have liners which significantly facilitate patient's daily activities and virtually replace bandages. To date, there has been no comparative study to evaluate changes in QoL in patients with CVD after CT using CIVIQ-20.

A prerequisite study completion in our sample was their full compliance with CT recommendations. Meeting this condition can often be an obstacle. According to Raiu et al., up to $63 \%$ of patients with CVD do not use CT. The numbers are similar in both sexes across all CEAP classes and are attributable to the impossibility to use CT, its lack of efficacy or non-adherence to treatment recommendations. In 1/3 of cases, non-adherence leads to the perceived lack of efficacy [33]. Non-adherence may be associated with perceived discomfort due to excessive skin dryness, itching, pressure or overheating sensation as well as difficulties putting on compression hosiery. It is also associated with lack of understanding how CT works and patient's level of education. For example, almost $82 \%$ of patients with primary education refuse to use CT $[30,33,34]$. However, the reasons for the lack of CT use or its misuse are not solely attributable to patients. Physicians, who fail to prescribe CT or insufficiently educate their patients on CT principles, are also partly to blame, which is reflected in survey-based studies [33]. Therefore, in our study, particular care was taken to educate the participants thoroughly on how CT works and how it should be used during the first visit. The study group consisted only of those who reported $100 \%$ adherence to $C T$ recommendations over the 6 -month period. This was crucial as only proper use of CT can reduce clinical symptoms and improve the quality of life in patients with CVD, which we have hopefully demonstrated. Perhaps our results will translate into more common use of this valuable treatment modality. Our study should encourage the use of CT in patients with CVD at all stages.

\section{Conclusions}

Compression therapy using ready-made compression hosiery significantly affects the quality of life in patients with chronic venous disease at all its stages, CEAP classes C1-C6. There was a significant QoL improvement across all domains ascertained using the SF-36v2 and CIVIQ-20 measures. Alongside appropriate compression hosiery selection, treatment adherence, i.e. wearing the 
compression product for long enough during a day, is a prerequisite for $\mathrm{CT}$ efficacy. Patient education on principles and detailed recommendations for using CT can help to ensure the optimum clinical effect and improved QoL.

\section{Conflict of interest}

The authors declare no conflict of interest.

\section{References}

1. Janbon C, Quere I. Jakość życia i praktyka lekarska w przewlekłej niewydolności żylnej. Farmacja Polska 2004; 60: 512-5.

2. Szewczyk M, Jawień A, Hildebrandt Z. Subjective understanding of health status among patients with chronic venous insufficiency - part I. Przegl Flebol 2005; 13: 175-81.

3. Cieślik B, Podbielska H. A survey of the quality of life questionnaires. Acta Bio-Optica et Informatica 2015; 21: 102-35.

4. Health-related quality of life and well-being. Foundation Health Measure Report. Healthy People 2020. Revised Nov 2010: 1-6.

5. Staszkiewicz W, Raciborski W, Słowiński P, Dąbek P. Zmiana jakości życia pacjentów z przewlekłą chorobą żylną po ośmiotygodniowym leczeniu preparatem Diosminex. Pol Surg 2011; 13: 5-10.

6. Eberhard RT, Raffetto JD. Chronic venous insufficiency. Circulations 2014; 30: 333-46.

7. Darvall K, Bate GR, Adam DJ, Bradbury A. Generic healthrelated quality of life is significantly worse in varicose vein patients with lower limb symptoms independent of CEAP clinical grade. Eur J Vasc Endovasc Surg 2012; 40: 341-4.

8. Launois R. A quality of life tool kit in chronic venous disease. Phlebolymphology 2015; 22: 33-41.

9. Launois R. Health-related quality of life scales specific for chronic venous disorders of the lower limb. J Vasc Surg Venous and Lymphat Disord 2015; 3: 219-27.

10. Berszakiewicz A, Sieroń A, Krasiński Z, et al. Compression therapy in venous diseases: physical assumptions and clinical effects. Adv Dermatol Allergol doi:10.5114/ ada.2019.86990.

11. Berszakiewicz A, Sieroń A, Krasiński Z, et al. Compression therapy in venous diseases current forms of compression materials and techniques. Adv Dermatol Allergol doi:10.5114/ ada.2019.86991.

12. Catarinella FS, Nieman F, Wittens C. An overview of the most commonly used venous quality of life and clinical outcome measurements. J Vasc Surg Venous Lymphat Disord 2015; 3: $333-40$.

13. Partsch H, Flour M, Smith PC, et al. Indications for compression therapy in venous and lymphatic disease consensus based on experimental data and scientific evidence. Int Angiol 2008; 27: 193-219.

14. Rabe E, Partsch H, Hafner J, et al. Indication for medical compression stockings in venous and lymphatic disorders: an evidence-based consensus statement. Phlebology 2018; 33: 163-84.

15. Partsch B, Partsch H. Compression therapy. In: VAS European Book of Angiology/Vascular Medicine. Catalano M, Pescrardy Z, Wutrecht JC, et al. (eds). $1^{\text {st }}$ edition. Aracne, Canternao, Italy 2018; 687-99.

16. Passman A, McLafferty R, Lentz M, et al. Validation of Venous Clinical Severity Score (VCSS) with other venous severity as- sessment tools from the American Venous Forum, National Venous Screening Program. J Vasc Surg 2011; 54: 2s-9s.

17. Jensen MP, Karoly P, Braver S. The measurement of clinical pain intensity: a comparison of six methods. Pain 1986; 27 : 117-26.

18. Launois R, Le Moine JG, Lozano FS, Mansilha A. Construction and international validation of CIVIQ-14 (a short form of CIVIQ-20), a new questionnaire with stable factorial structure. Qual Life Res 2012; 21: 1051-8.

19. Andreozzi GM, Cordova R, Scomparin MA, et al. Effects of elastic stocking on quality of life of patients with chronic venous insufficiency. Int Angiol 2005; 24: 325-9.

20. Launois R, Mansihla A, Jantet G. International psychometric validation of chronic venous disease quality of life questionnaire (CIVIQ-20). Eur J Vasc Endovasc Surg 2010; 40: 783-9.

21. Sinozic T, Bazdaric K, Sverko D, et al. Validation of the Coroatian version of CIVIQ quality of life questionnaire in in patients with chronic venous disorders. Croat Med J 2017; 58: 292-9.

22. Górski G, Woźniak W, Hara M, et al. Subjective patient assessment of varicose vein surgery vs changes in health-related quality of life. Pol Przegl Chirur 2006; 78: 35-50.

23. Kahn SE, M'lan CE, Lamping D, et al. Relationship between clinical classification of chronic venous disease and patientreported quality of life: results from an international cohort study. J Vasc Surg 2004; 39: 823-8.

24. Araujo Farias Dias TY, Fernandes Costa IK, Dantas Medeiro Melo M, et al. Quality of life assessment of patients with and without venous ulcer. Rev Lat Am Enfermagem 2014; 22: 576-81.

25. Kaplan RM, Criqui MH, Denenberg JO, et al. Quality of life in patients with chronic venous disease: San Diego population study. J Vasc Surg 2003; 37: 1047-53.

26. Vasquez MA, Munschauer CE. Venous clinical severity score and quality of life assessment tools: application to vein practice. Phlebolymphology 2010; 17: 108-15.

27. Fiodorenko-Dumas Ż, Paprocka-Borowicz M, Dumas I, Korcz-Trzęsicka A. Jakość życia i stan zdrowia u pacjentów z obrzękiem kończyn dolnych. Med Og Nauk Zdr 2012; 18 : 247-51.

28. Brtan Romic A, Brtan A, Romic I, et al. Quality of life and perception of disease in patients with chronic leg ulcer. Acta Clin Croat 2015; 54: 309-14.

29. Herber OR, Schnepp W, Rieger M. A systemic review on the impact of leg ulceration on patient quality of life. Health Qual Life Outcomes 2007; 5: 44.

30. Ozdemir OC, Sevim S, Duygu E, et al. The effects of shortterm use of compression stockings on health-related quality of life in patients with chronic venous insufficiency. J Phys Ther Sci 2016; 28: 1988-92.

31. van der Velden SK, Biemans AA, Nijsten T, Sommer A. Translation and validation of the Dutch Veines-Qol/Sym in varicose vein patients. Phlebology 2014; 29: 227-35.

32. Demczyszak I, Sutkowska E, Jasiak M, et al. The impact of compression garments on the quality of life in patients with chronic venous disease. Physiotherapy 2016; 24: 19-22.

33. Raju S. Compliance with compression stockings in chronic venous disease. Phlebology 2008; 15: 103-6.

34. Reich-Schupke S, Murmann F, Altmeyer P, Stücker M. Quality of life and patients' view of compression therapy. Int Angiol 2009; 28: 385-93. 